\title{
Evaluation of Open Educational Resources (OER) Use in Construction Management Technology Courses
}

\section{Dr. Michael Shenoda, State University of New York, College of Technology at Farmingdale}

Michael Shenoda is currently an assistant professor in the Department of Architecture and Construction Management at Farmingdale State College in New York. He has previously served as a faculty member at other institutions, totaling over 13 years in civil engineering and construction management education. Michael is a member of several professional organizations, including American Society of Civil Engineers (ASCE), Institute of Transportation Engineers (ITE), and American Society of Engineering Education (ASEE). He has also been inducted into Tau Beta Pi, the National Engineering Honor Society, and Chi Epsilon, the Civil Engineering National Honor Society. He has carried out research in several areas, including advanced traffic signal control, construction management, and sustainability in construction and civil engineering. Michael has also worked in the engineering industry for several years, as both a design engineer and construction inspector. He is a licensed professional engineer in New Jersey and Texas, and a LEED (Leadership in Energy and Environmental Design) Accredited Professional in Building Design and Construction. 


\section{Evaluation of Open Educational Resources (OER) Use in Construction Management Technology Courses}

Abstract

Access to educational programs in Construction Management Technology can be limited by the high cost of textbooks, software, and other proprietary materials. The use of Open Education Resources (OER), which are materials that have low or no cost for academic use, can help address the issue of access. Construction Management Technology courses can realize this benefit relatively easily, as the needed resources may often be accessed or created based on materials available from public agencies at all levels of government. There are several goals other than reduced cost that should be addressed by OER use in Construction Management Technology. These include: (1) meeting required student learning outcomes, (2) improving student attitudes regarding educational access, and (3) fostering adaptation of the material to enhance student learning and provide current information. Having previously established a framework for evaluating the effectiveness of implementing OER in a Construction Management Technology course, the current work reports on the performance of OER use in an estimating course. Two sections of the course being offered in the Fall 2019 semester are evaluated herein based on cost of materials and achievement of the three goals outlined. These are compared to a non-OER section of the course also being offered in Fall 2019, as well as performance in offerings of the same estimating course before OER implementation.

\section{Background}

Construction Management involves the study of courses in areas of practice such as plan reading and production, cost estimating, safety, scheduling, and project management. Students are often required to purchase textbooks, equipment, and software for these courses at great expense. The author has previously considered [1] the high level of expenses for engineering and technology, in general, and Construction Management, in particular, and the high rate of increase in the cost of these over time through a number of sources. These included costs of over $\$ 300$ for individual textbooks [2] and over $\$ 1200$ a year [3], and a rate of increase of three times the overall rate of inflation, since 1970 [4]. Negative consequences of these were also outlined, including direct consequences like avoidance of textbook purchases [5] or avoidance of necessary courses with high textbook costs [6], and poor course performance [7]. Extended consequences, like delays in student graduation, increases in student attrition, and avoidance of "high-cost" majors (like engineering and technology) [6] were also considered.

These costs and consequences lead to, as also previously considered, measures intended to mitigate or avoid them. These included more illicit or undesirable measures, like textbook sharing [7], illegal downloading and/or copying of materials [5], and use of unsuitable alternative materials [6]. However, a number of more carefully considered and/or market-based measures were also laid out, such as used textbooks [9], financial aid for textbooks purchases [10], increased library lending [11], textbook rentals [12], e-textbooks [13], and "lean" or custom textbooks [2]. 
A more novel and recently explored measure to alleviate textbook expenses in courses is the use of Open Educational Resources, or OER, which we defined by UNESCO as "teaching, learning and research materials in any medium - digital or otherwise - that reside in the public domain or have been released under an open license that permits no-cost access, use, adaptation and redistribution by others with no or limited restrictions." [14] It was previously considered by the author [1] that OER efforts to date have been focused towards the general sciences, social sciences, mathematics, and liberal arts. This has led to a wide availability of OER repositories like the OER Center for California [15], California State University [16], Washington State University [17], OpenStax [18], and SUNY OER [19]. However, many of the resources are in these are course planning materials like lesson plans, assignments, syllabi, or lectures rather than textbook-like references.

The dearth of OER for engineering and technology, particularly with regard to textbooks, was considered, as well. Despite the combination of high textbook costs in these fields and limited availability, only a few repositories, like Massachusetts Institute of Technology's MIT Open CourseWare repository [20] and a repository at New Jersey Institute of Technology [21] contain any OER. Almost no examples for Construction Management were found to exist. This led to a proposal by the author of the use of resources from governmental agencies as OER materials in Construction Management courses. Agencies examined for potential OER included the General Services Administration [22], U.S. Army Corps of Engineers [23], and U.S. Government Accountability Office [24].

On the basis of availability of high-quality open access materials for the course, and impact to cost of current course materials. The author chose a cost estimating course, CON 357 - Quantity Surveying and Costing, was selected for OER implementation. The typical cost for materials for the course are shown in Table 1. These were tabulated with the understanding that there is some variety in the quality and cost of available materials (although this is somewhat limited in the area of cost estimating relative to other construction management topics). These were also considered in the context of changing materials and cost through historical offerings of the course.

Table 1. Typical course material costs for CON 357 - Quantity Surveying and Costing.

\begin{tabular}{|l|l|}
\hline Resource & Cost \\
\hline \hline Textbook & \\
\hline $\begin{array}{l}\text { Construction Estimating Using Excel, 3 } \\
\text { Edition by Steven Peterson }\end{array}$ & $\$ 164.48$ (via Amazon.com [25]) \\
\hline Software (for electronic quantity takeoffs) & \\
\hline Bluebeam Revu eXtreme 2018 Academic & $\$ 99.00$ (via shop.bluebeam.com [26]) \\
\hline Cost data reference & \\
\hline RS Means Online Cost Data Student Package & $\$ 45.00$ (via rsmeans.com [27]) \\
\hline \hline TOTAL & $\$ 308.48$ \\
\hline
\end{tabular}


A comprehensive review of materials available on an OER basis was also considered for the course [1]. Availability, quality, and cost were all qualities of the materials taken into account for the tabulation of OER made in Table 2. Despite not being to completely eliminate expenses for the course with the selected set of materials, a significant reduction in cost of over $85 \%$ from the typical cost from Table 1 was achieved. This cost could potentially be reduced further or eliminated based on further developments in cost estimating literature.

Table 2. OER course material costs for CON 357 - Quantity Surveying and Costing.

\begin{tabular}{|l|l|}
\hline Resource & Cost \\
\hline \hline Textbook & \\
\hline U.S. Marine Corps MCRP 3-40D.12: Construction Estimating [28] & $\$ 0.00$ \\
\hline Software (for electronic quantity takeoffs) & \\
\hline Smithsonian Institution Construction Cost Estimating Form [29] & $\$ 0.00$ \\
\hline Cost data reference & \\
\hline RS Means Online Cost Data Student Package Non-OER total (from Table 2) & $\$ 308.48$ \\
\hline \hline Cost reduction & $-85.4 \%$ \\
\hline \hline
\end{tabular}

With the materials selected for the course, an evaluation framework was developed for the course. The framework was developed with the intent to be applicable to any Construction Management course, and contains both a quantitative and a qualitative aspect. The quantitative aspect is meant to evaluate objective measures of course performance, and the qualitative aspect is meant to evaluate more subjective measures (i.e. attitudes) regarding OER among the students taking the course. This framework will be discussed in later sections, as the results from the evaluation are presented.

The qualitative evaluation of the course was conducted at least once per year from the 2013-2014 academic year to the 2018-2019 academic year. The course was then taught and evaluated in three sections during the Fall 2019 semester. Two of the sections were offered using OER, and the results for these are presented as one combined set of performance measures for both sections. One section of the course was taught using the traditional materials, and is presented as a "control". (It is understood that the results of the qualitative evaluation should be considered unscientific, due to the inability of the author to properly control for variations in such characteristics as institution, time aspects of the classes, continuous improvement measures over successive offerings, etc.) The qualitative evaluation was conducted for only the OER sections of the Fall 2019 semester. The results are presented to convey a general sense of student attitudes regarding OER within the course, rather than for a comparative perspective to those who had not been in OER sections of the course.

\section{Quantitative Evaluation}

The quantitative evaluation for OER application is based on four course objectives, for the Quantity Surveying and Costing course, which are outlined in Table 3. The course objectives are 
plans, assessment tools (exams, exercises, and projects), and general teaching techniques.

Despite these differences and the variations arising from them, there is a general consistency to be seen for each objective, as well as at least adequate performance across all objectives.

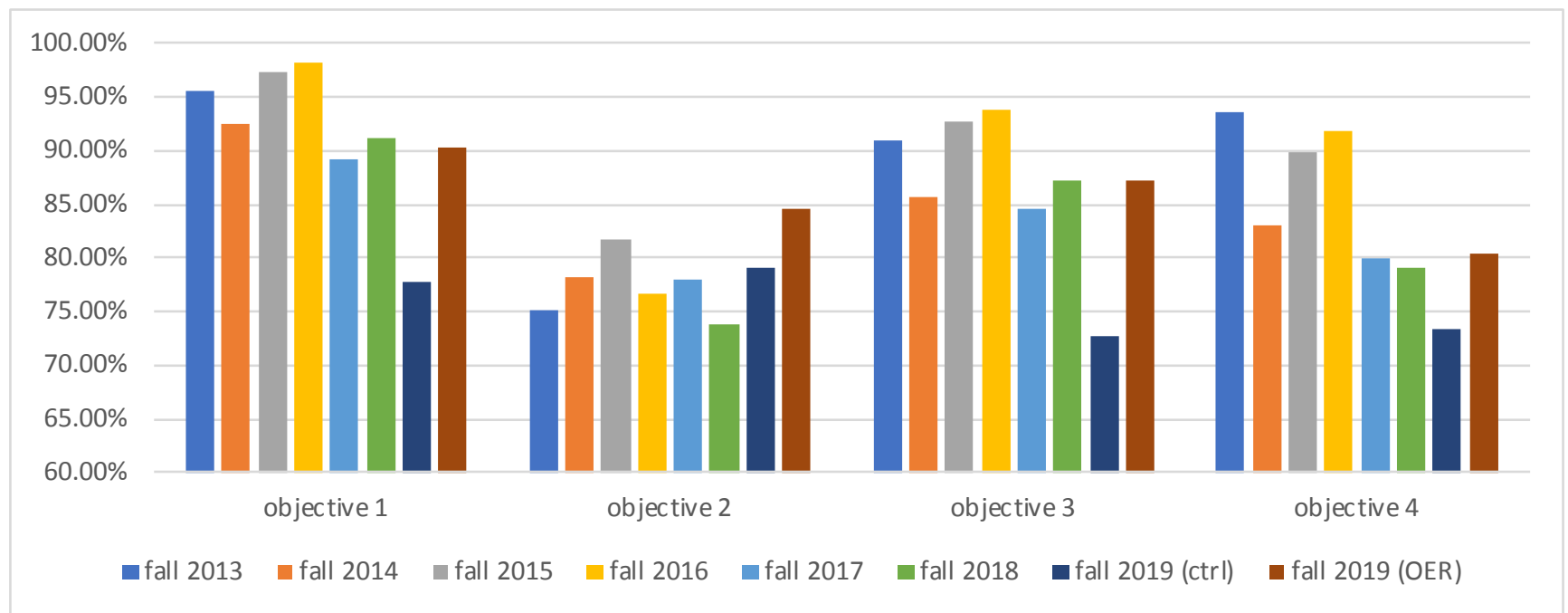

Figure 1. Tracking of student performance in course objectives for estimating course (CON 357)

With this in mind, the goal of OER implementation for student performance, at least at the outset, is not to exceed previous levels, but to reasonably match them. This should demonstrate that there is not a degradation in student achievement arising from the use of non-traditional materials. It is evident from the performance tracking seen in Figure 1 that this goal has been achieved.

The results for the fall 2019 non-OER offering are somewhat lower than those for the OER offerings and for previous offerings of the CON 357 course. This may be due to a focus by the author on implementing the OER offerings and preparing the materials for those offerings. The largest drop-off in performance seems to be for Objective 1. This may be so because most of the work towards Objective 1 in the course is done towards the beginning of the course. An adjustment to allow the OER and the non-OER pace to come together over the length of the semester may be a factor.

Another factor that could explain the drop-off in Objective 1 could be the difference in its nature relative to the others. Objective 1 is a concept-based objective, whose results (explanation) must be evaluated subjectively. Objectives 2 and 3 are method-based, and their results (calculations) can be evaluated more objectively. Objective 4 is a combination, or synthesis-based, objective, which may be best related to real-world work tasks and/or product. Objectives 2 and 3 may be the easiest to transfer and evaluate in Construction Management courses, both traditionally and using OER. Concept-based objectives, like Objective 1, are more difficult to achieve, and may require more extensive review of the OER materials to properly convey to students.

The relatively high achievement of Objectives 2 and 3 is notable, though, for the OER offerings. This achievement may be based on two factors: (1) the focus of the selected OER materials on 
estimation methods and (2) the focus of the author on conveying the method in the course. As a technology-based course, these objectives may be considered to be vital and easier to grasp, both in the context of the course itself and that of the curriculum as a whole. Nevertheless, the concept-based (Objective 1) and the synthesis-based (Objective 4) objectives are both (1) at acceptable levels (e.g. for CQI considerations) and (2) addressable through CQI considerations of the OER materials.

\section{Qualitative Evaluation}

The author had previously considered the importance of evaluating the qualitative, as well as the quantitative, aspects of the course. The drastic nature of the shifting of materials and a possible perception of degradation in course quality with a shift to "free" materials were cited. Two major resources for qualitative OER evaluation were considered: (1) Lumen Learning's "Annual OER Report Card" [31] and (2) the Open Textbook Network's Guidebook to Research on Open Educational Resources Adoption [32]. The Guidebook provided a number of evaluation areas on the basis of, not only cost, student and faculty use, but perceptions of OER (mainly focused on student perception). The Guidebook also provided a menu of survey questions that could directly be provided to students to evaluate these areas. Thus, the Guidebook was selected as the primary source of questions used to evaluate the "attitudes" of students regarding OER implementation in the CON 357 course. The survey questions used are outlined in Table 4.

Table 4. Survey questions for evaluation of impacts of OER implementation.

\begin{tabular}{|l|l|}
\hline Q\# & Question \\
\hline 1 & In general, how often do you purchase the required texts for the courses you take? \\
\hline 2 & How much do you typically spend on texts each semester? \\
\hline 3 & For a typical course, how often do you use the required texts? \\
\hline 4 & Did you purchase any texts for this course? \\
\hline 5 & How much did you spend on texts for this course? (If yes to Q\#5) \\
\hline 6 & $\begin{array}{l}\text { Why did you not purchase the texts for this course? (select all that apply) } \\
\text { (If no to Q\#5) }\end{array}$ \\
\hline 7 & How often did you use the texts for this course during the semester? \\
\hline 8 & How would you rate the quality of the texts used for this course? \\
\hline 9 & $\begin{array}{l}\text { Imagine a future course you are required to take. If two different sections of this course were } \\
\text { offered by the same instructor during equally desirable time slots, but one section used texts } \\
\text { similar to those used in this course and the other used traditional published texts, which section } \\
\text { would you prefer to enroll in? }\end{array}$ \\
\hline
\end{tabular}

The survey was made available to all students in both sections of the CON 357 course in which OER was implemented. There was a total of 66 students enrolled in both sections, with 50 students responding to the survey, for a response rate of approximately $76 \%$. This relatively high response rate should allow the responses to be representative of the "attitudes" of the students in the sections with OER implementation. 
The responses to Questions 1 through 3 are presented in Figures 2 through 4 . These three questions were intended to surmise the general nature of the use of textbooks in the course. They may be considered to be indicative of students in Construction Management and/or Architectural Engineering Technology curricula, as the CON 357 course is required in those curricula, and all of the students in both those sections majored in those curricula.

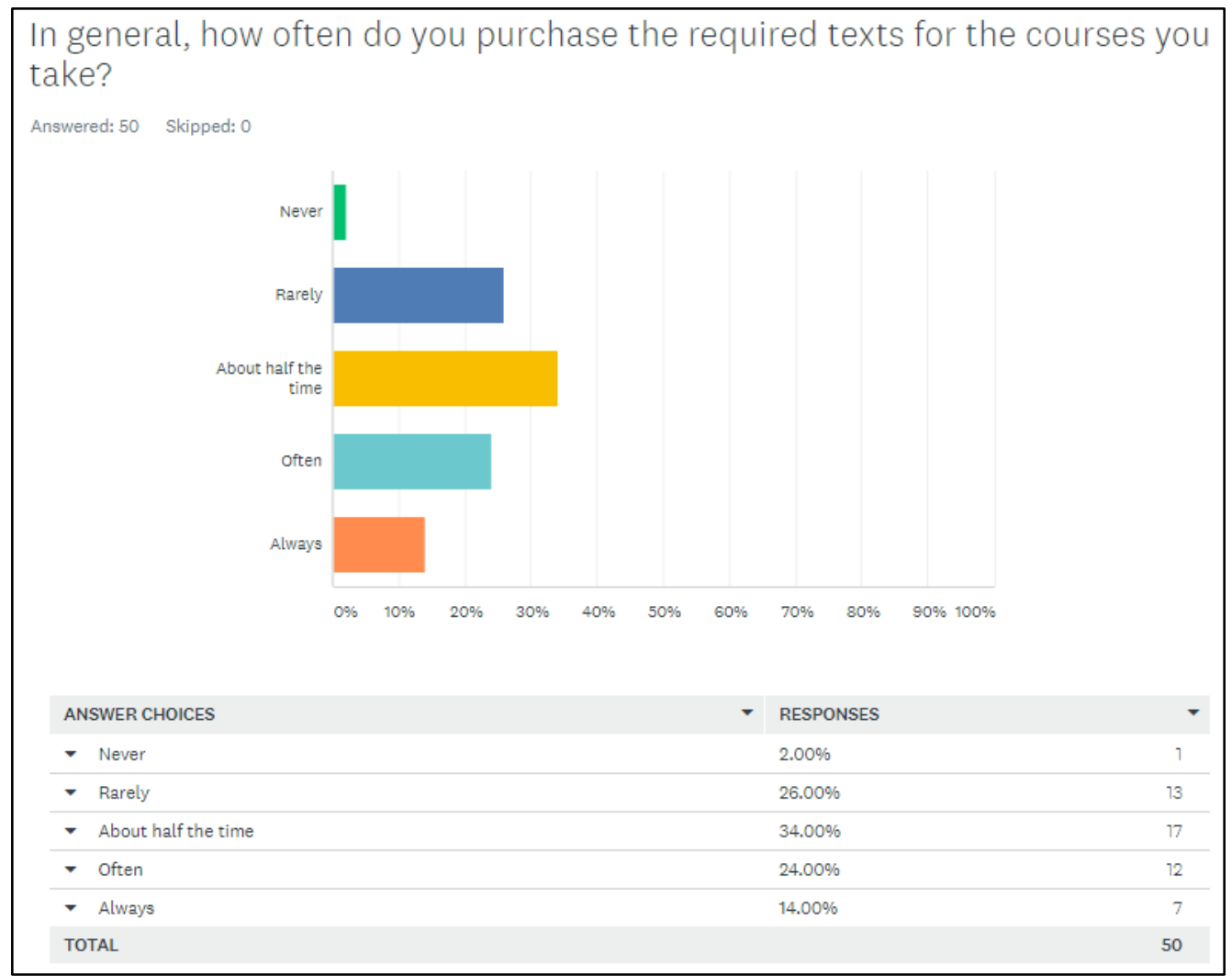

Figure 2. Responses to Question 1 for qualitative survey of OER sections of CON 357 


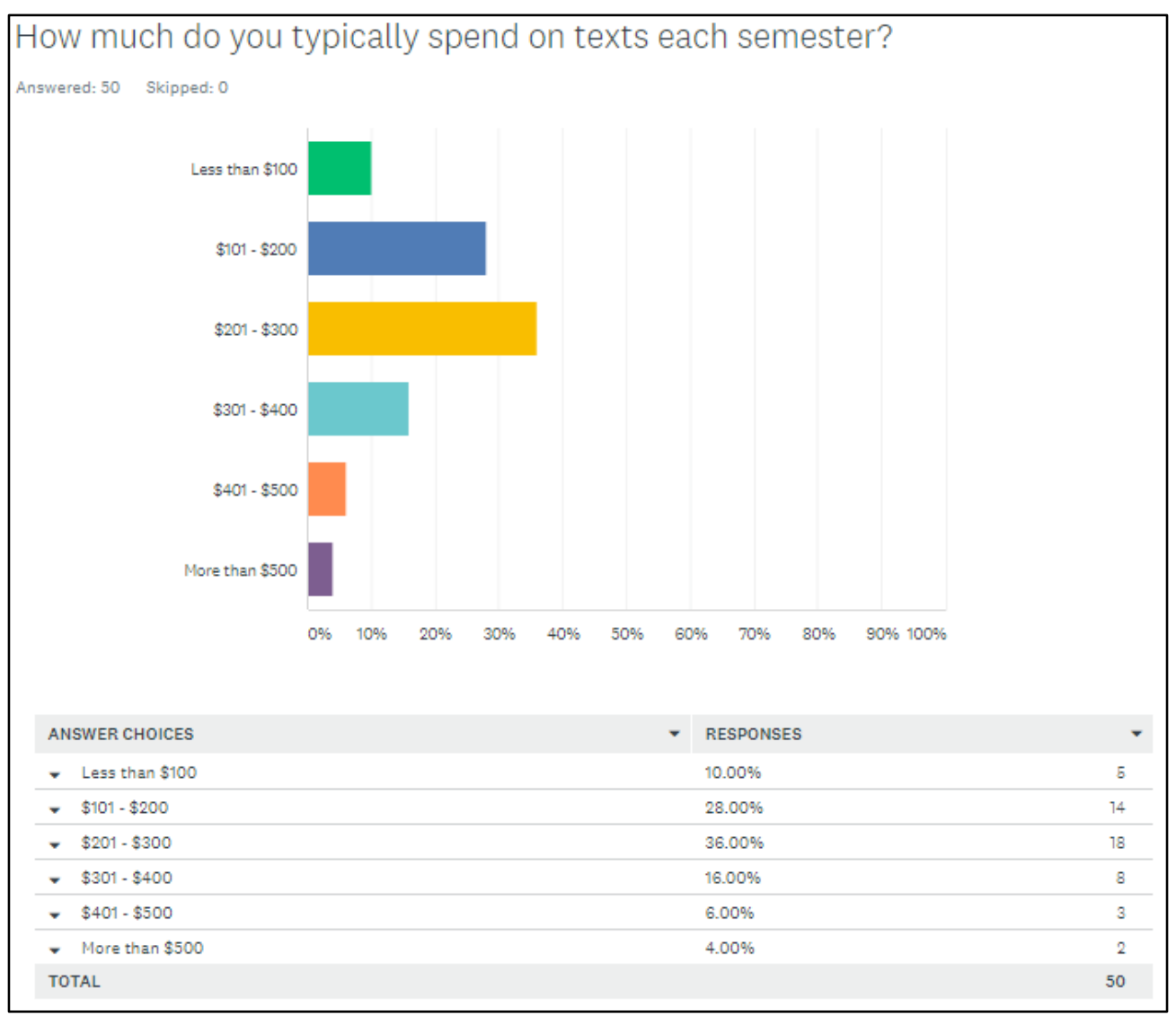

Figure 3. Responses to Question 2 for qualitative survey of OER sections of CON 357

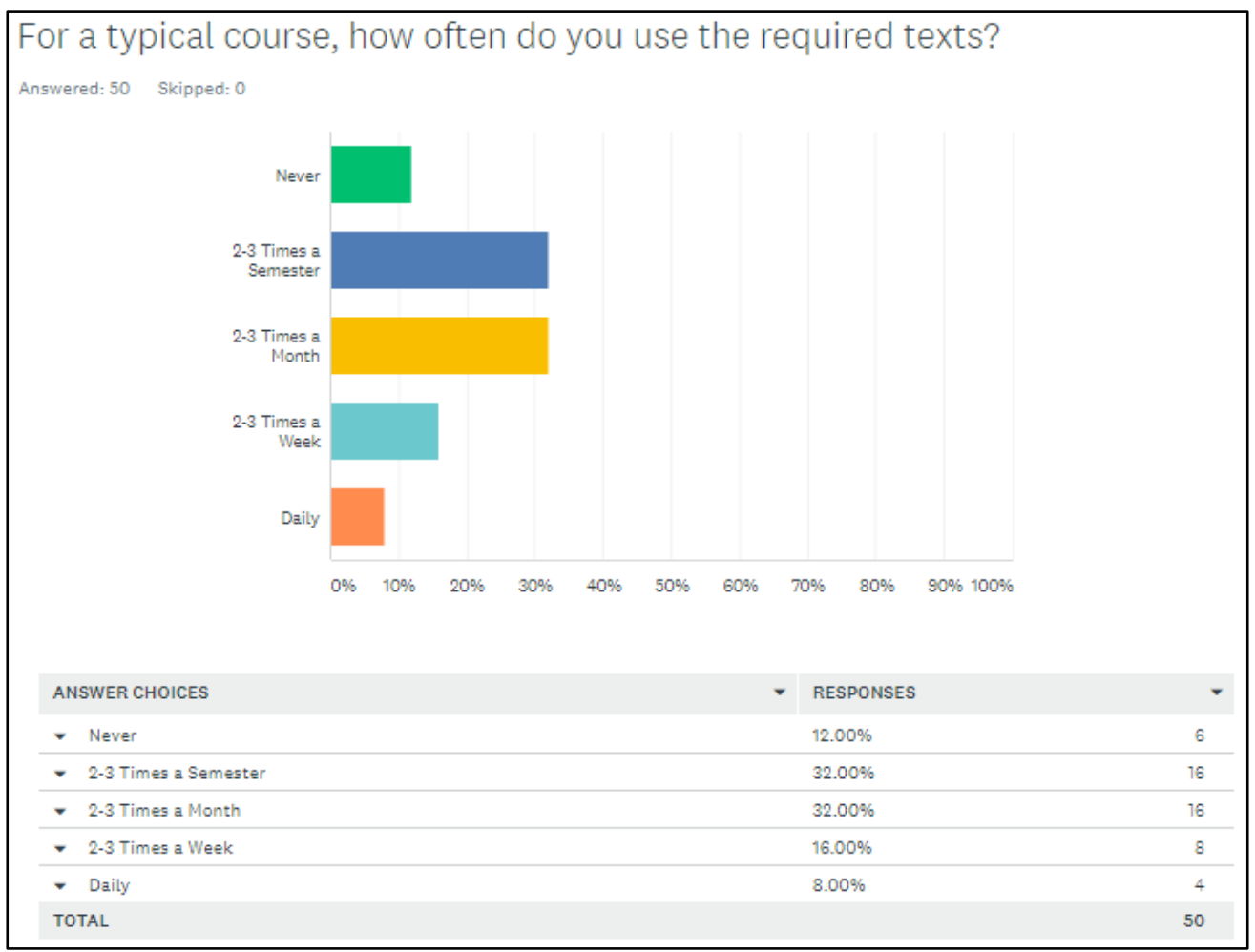

Figure 4. Responses to Question 3 for qualitative survey of OER sections of CON 357 
The responses to Questions 1 through 3 demonstrate student demand, based on desire and/or need, for the textbooks in courses in the curriculum. The spending level is consistent with the references cited in the "Background" section for a majority of the students. The potential for benefit from OER implementation in the course is evident in these responses.

The responses to Questions 4 through 7 are presented in Figures 5 through 8 . These three questions were intended to surmise the particular nature of student textbook choices and use for the CON 357 course with OER implementation. The responses would be indicative of the need and spending of student purchases of textbooks in the course.

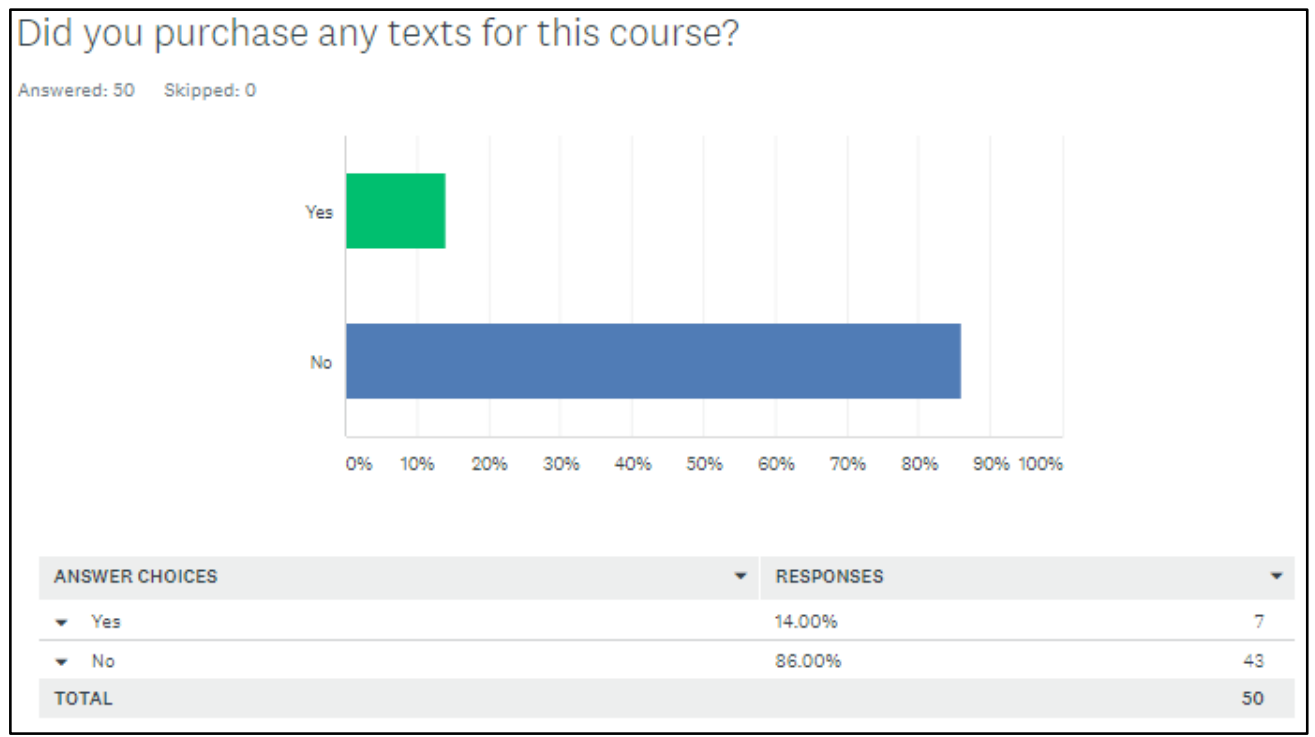

Figure 5. Responses to Question 4 for qualitative survey of OER sections of CON 357 


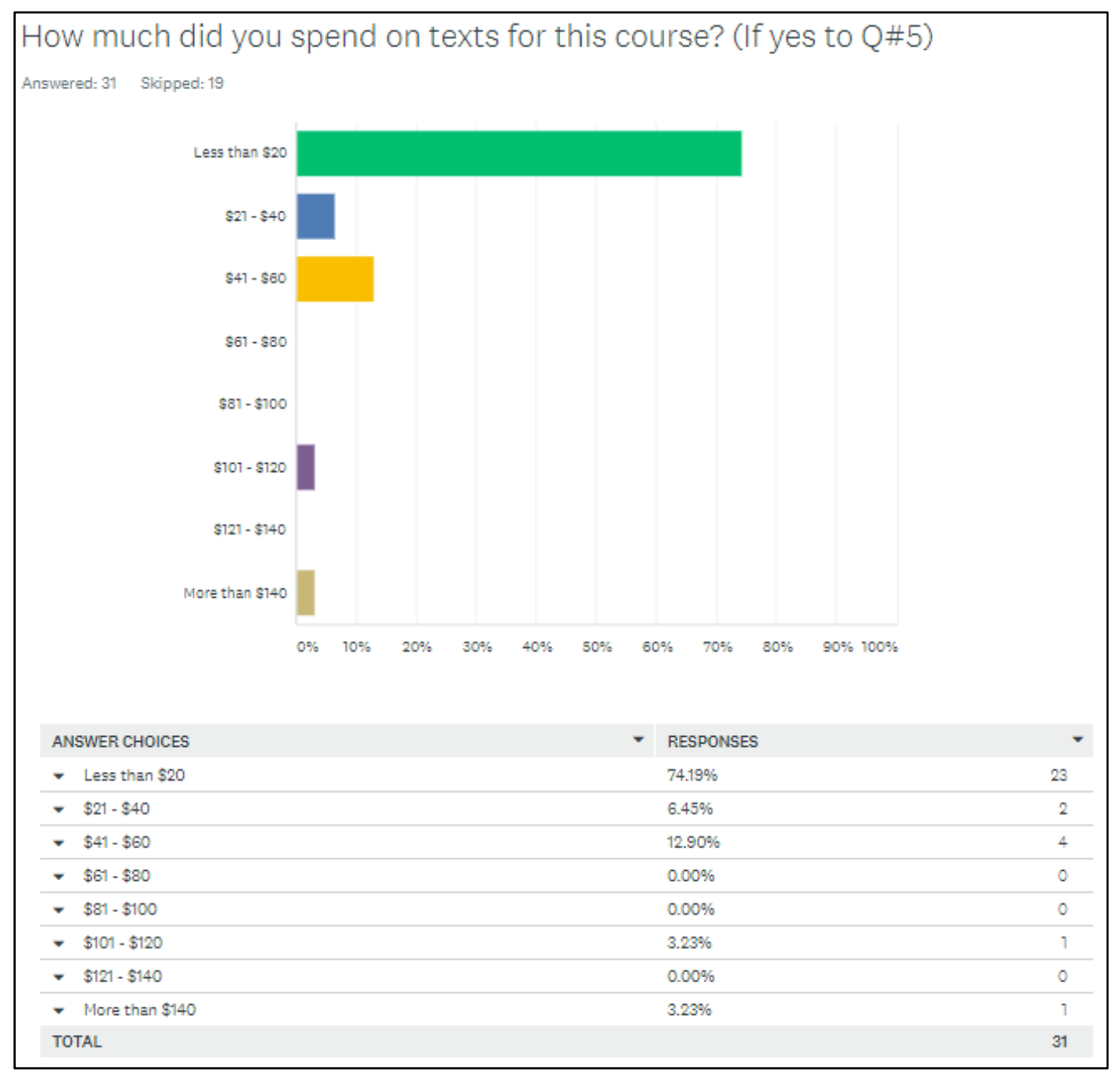

Figure 6. Responses to Question 5 for qualitative survey of OER sections of CON 357 


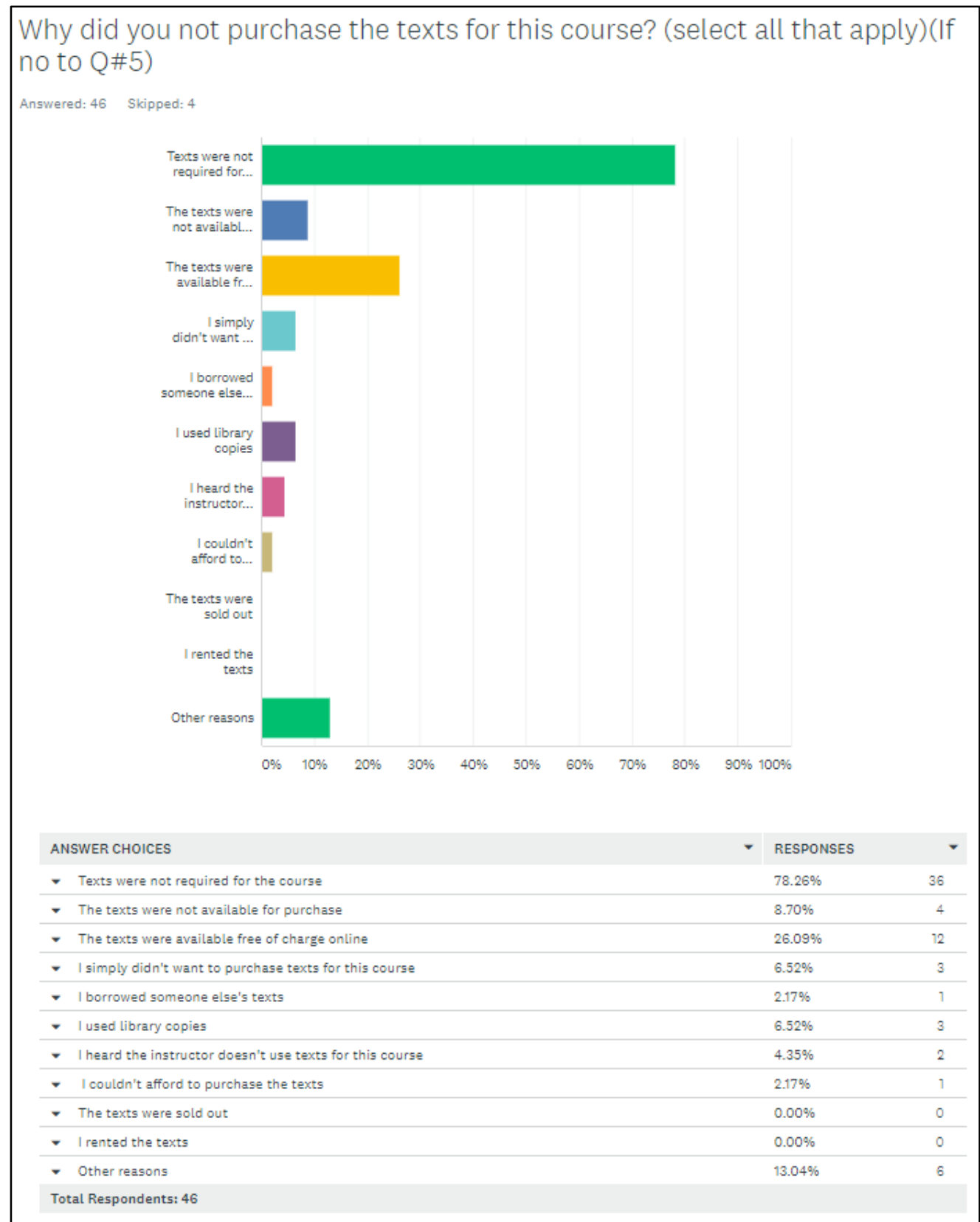

Figure 7. Responses to Question 6 for qualitative survey of OER sections of CON 357 


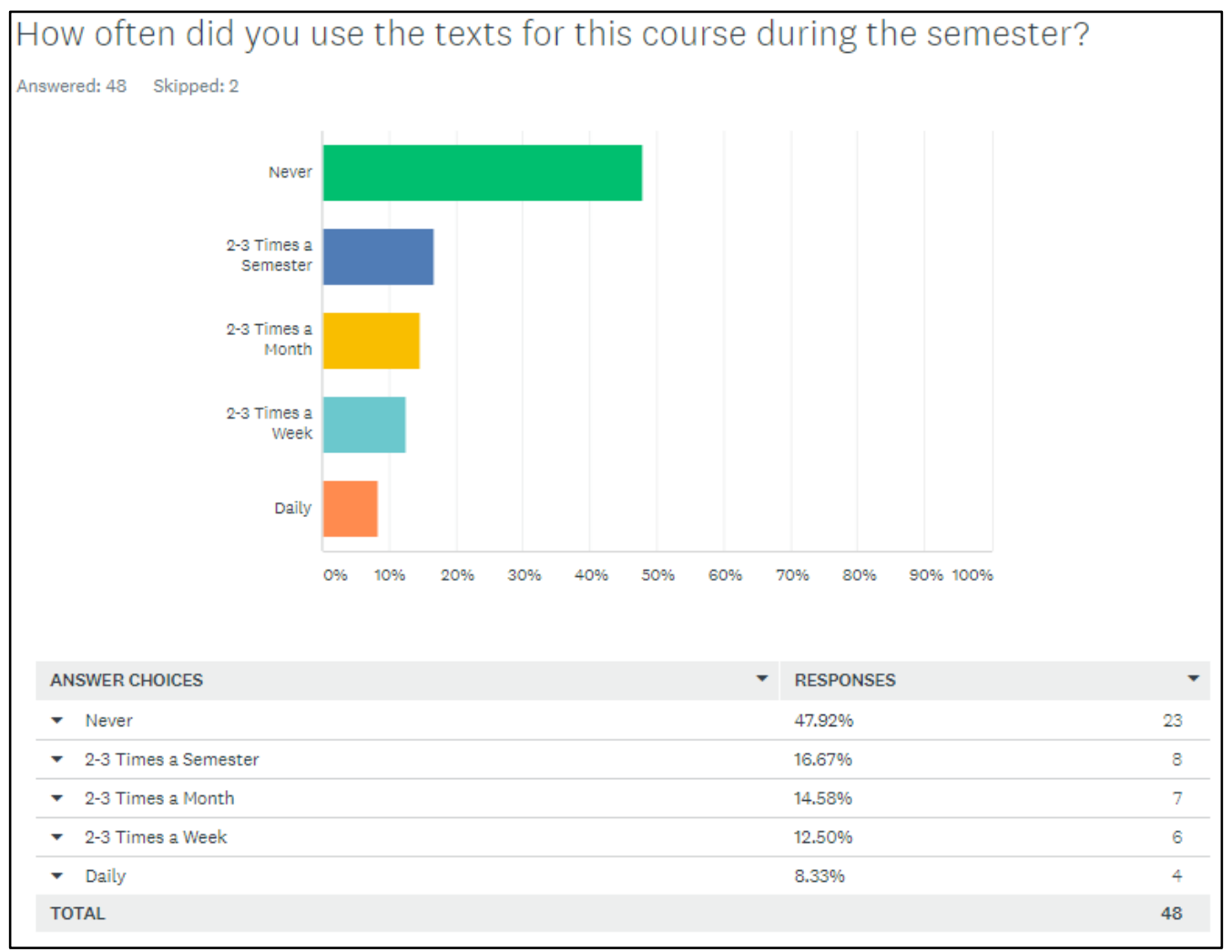

Figure 8. Responses to Question 7 for qualitative survey of OER sections of CON 357

The responses to Questions 4 through 7 demonstrate the reduced necessity students felt to purchase or use textbooks for the sections of the course with OER implementation. These responses might be self-evident in that the instructor would not require texts, generally, in OER courses. However, if the OER materials are not selected or implemented properly, students may not feel that they are sufficient to address the knowledge that they feel should be provided in the course. They would thus "self-select" materials that would replace or supplement the OER materials. This generally did not occur in this implementation, allowing the financial benefits of the implementation to be more fully realized.

The responses to Questions 8 and 9 are presented in Figures 9 and 10. These two questions may be considered to surmise the overall attitudes of the students about OER implementation in the CON 357 course. Coming after the previous questions, and not before or in the absence of those questions, they should have given the students the opportunity to consider the purpose of the OER implementation in both reducing the cost of taking the course and preserving the quality of the course materials. 


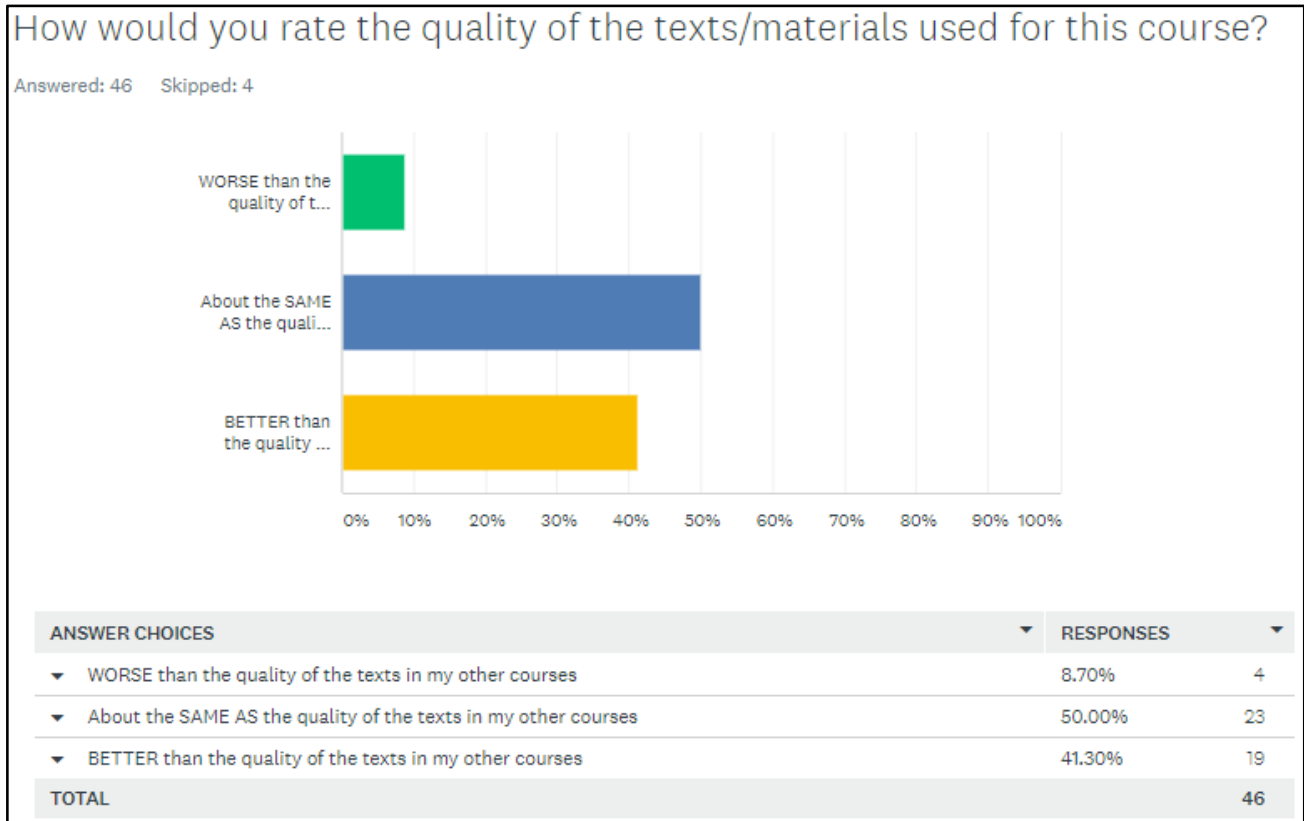

Figure 9. Responses to Question 8 for qualitative survey of OER sections of CON 357

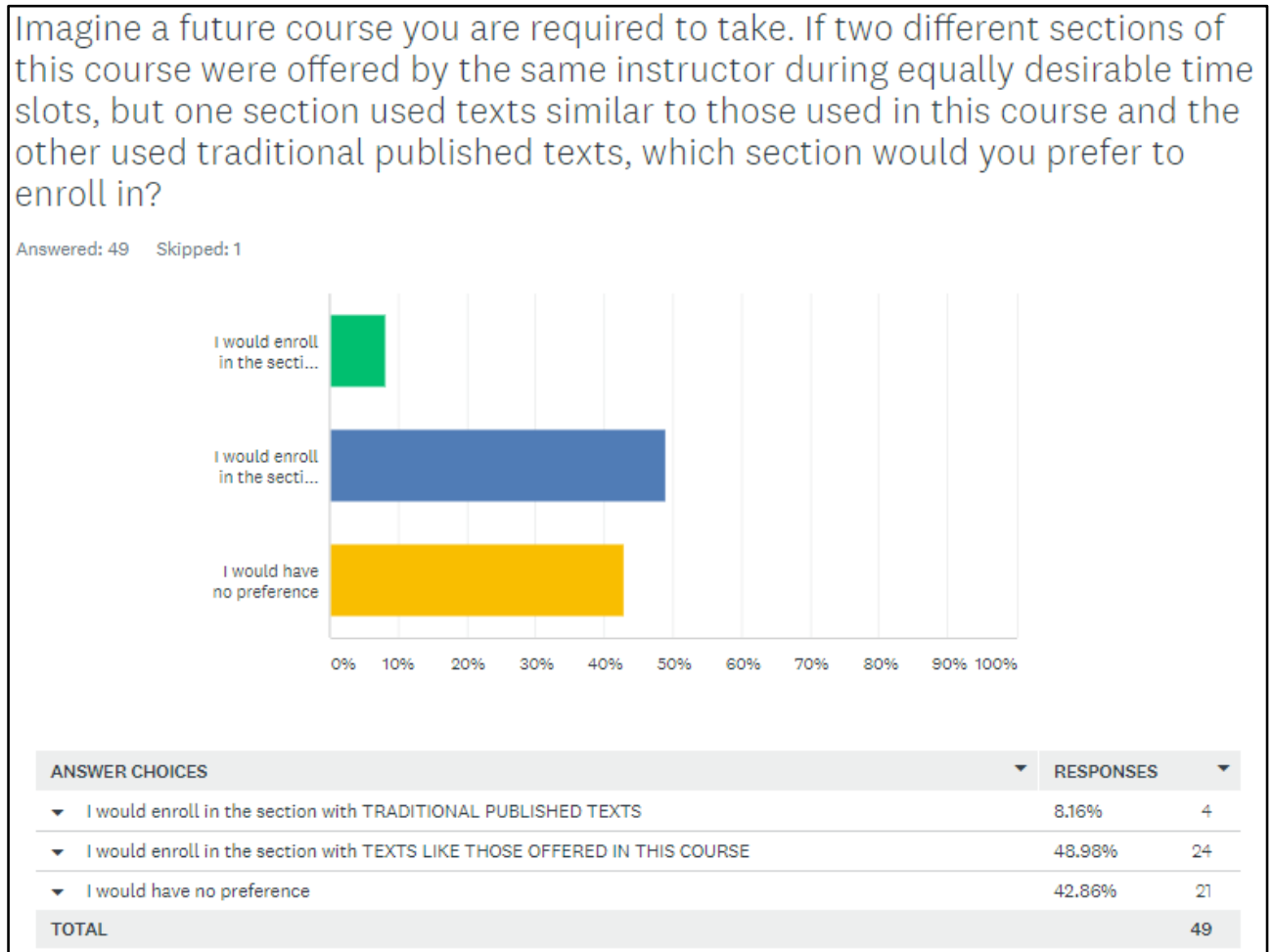

Figure 10. Responses to Question 9 for qualitative survey of OER sections of CON 357

The responses to Questions 8 and 9 demonstrate the effectiveness of the OER implementation from an "attitudinal" standpoint. Students felt, as a vast majority, that the OER materials matched or exceeded the quality of the traditional materials, as used in the CON 357 course. Students, through their responses to Question 9, also indicated that OER implementation could mitigate course avoidance on the basis of textbook costs. 


\section{Conclusions and Further Considerations}

In setting up the framework for OER implementation, achievement of two main goals of the implementation intended to be discovered by the evaluation. These were (1) improvement of access to course materials through cost reduction and (2) maintenance of course quality. The implementation appeared to achieve these goals, based on the evaluation.

As far as improvement of access to course materials, students indicated various levels of spending through Question 5 of the qualitative survey. However, these were clearly greatly reduced from the original intended level of spending outlined in Table 1. Assuming that students, on average, ended up spending at the level indicated in Table 2, the 66 students in the 2 OER sections of CON 357 should have saved a total of approximately $\$ 17,390$ in textbook costs.

In terms of maintenance of course quality, the quantitative evaluation is the clearest expression of achievement. Students were able to maintain, or even exceed, performance for the course objectives in the OER sections of CON 357. Just as importantly, per the qualitative evaluation, students used the OER materials in a manner consistent with traditional materials, and they perceived the course quality to be as good or better than with traditional materials

A larger goal of this implementation is to assess the viability of implementing, and evaluating, OER implementation in other Construction Management courses. Instructors and administrators, in particular, will be concerned with maintenance of course quality (certainly, for instance, for the purpose of ABET program evaluation). Consistency of the achievement of course quality though both qualitative and quantitative measures in this evaluation speaks to the confidence that may be had in using a framework based on ABET-mapped course objectives to see that course quality is maintained. The relationship of the results of the qualitative evaluation to previous research into the effects of high textbook prices is also reassuring. The results of the evaluation herein suggest that, not only can OER implementation be effective in other Construction Management courses, but that the framework presented previously by the author [1] and used herein can be used to evaluate other Construction Management courses. Such implementations, and the evaluations of them, within our institution will be a subject of future consideration.

The author had also previously posited the improvements to performance within an individual course should be considered as a long-term goal of OER implementation. Three means of doing this after OER implementation were considered:

1. standard CQI improvements, as outlined in the "Background" section

2. CQI-type improvements in direct response to OER implementation (e.g. changing lesson plans or assessment tools to better align to open-source materials)

3. changes to the OER materials themselves

Some improvements were already seen in the first OER offering of CON 357, as the author was aware of the importance of conveying methods in the course, and focused on these in the preparation and selection of OER materials. This seemed to lead to an increase in performance in the method-based objectives for the course. However, OER Commons states the use of OER is "about participation and co-creation." [33] The evaluation herein, assessment tools, institutional 
student evaluations, and other tools, are, thus, indeed being used to adapt the OER materials. OER materials, while starting with widely available sources, should evolve to be unique to each course, each instructor, and each student body. Therefore, the evolution of OER materials within the same Construction Management course, and the resulting effects, are a subject for future consideration, as well.

\section{References}

[1] Shenoda, Michael. Applicability of Open Educational Resources (OER) in Construction Engineering. Presented at 2019 ASEE Annual Conference and Exposition.

https://peer.asee.org/32319

[2] Institute of Industrial and Systems Engineers. "Leaning Out Textbook Costs" Industrial Engineer, August 2015

[3] Career Igniter. "How Much Does Civil Engineering School Cost?” 2019. https:/www.careerigniter.com/questions/how-much-does-civil-engineering-school-cost/

[4] The Economist. "Why textbooks cost so much" August 16, 2014.

[5] Stein, S., S. Hart, P. Keaney, and R. White. Student Views on the Cost of and Access to Textbooks: An Investigation at University of Otago (New Zealand). Open Praxis. Vol. 9, Issue 4, Oct.-Dec. 2017. pp. 403-419.

[6] Donaldson, R.L. and E. Shen. 2016 Florida Student Textbook and Course Materials Survey. Florida Virtual Campus. 2016.

[7] McKenzie, L. "Study: High Textbook Prices Lead to Poor Grades" Inside Higher Ed., Sept. 20, 2017. https:/www.insidehighered.com/quicktakes/2017/09/20/study-high-textbookprices-lead-poor-grades

[8] Paterson, James. "Survey: Students say textbook costs have 'big impact' on finances." EducationDive, July 26, 2018. https:/www.educationdive.com/news/survey-students-saytextbook-costs-have-big-impact-on-finances/528744/

[9] Chaker, A. M. "Efforts mount to cut costs of textbooks; as prices rise at twice the rate of inflation, states pass laws to encourage cheaper alternatives." Wall Street Journal, Sept. 28, 2006.

[10] Beal, B.D., and J. Tarter. "Flat World Knowledge and the College Textbook Market: A Revolution?” Journal of Case Studies, Vol. 31, No. 2, November 2013. pp. 98-113.

[11] Gibbs, D., and J. Bowdoin. TextSelect: Purchasing Textbooks for Library Reserves. Against the Grain, Vol 26, Issue 5, Article 13, 2014.

[12] Benson-Amer, R., J. Sarakatsannis, and K. Wise. "The future of textbooks." Social Sector, McKinsey \& Company, August 2014. 
[13] Miller, J.R., A.W. Nutting, and L. Baker-Eveleth. "The Determinants of Electronic Textbook Use among College Students" The American Economist, Vol. 58, No. 1, 2013. Pp. 41-50.

[14] United Nations. UNESCO Open Educational Resources. 2019. https:/en. unesco.org/themes/building-knowled ge-societies/oer

[15] OER Center for California. The Community College Consortium for Open Educational Resources. https:/www.cccoer.org/

[16] California State University. MERLOT Collection. https $/ /$ www.merlot.org/merlot/index.htm

[17] Washington State University. Open Course Library. http $/ /$ opencourselibrary.org/

[18] Rice University. OpenStax. https:/cnx.org/

[19] State University of New York. SUNY OER Services. https:/oer.suny.edu/

[20] Massachusetts Institute of Technology. MIT Open CourseWare. https:/ocw.mit.edu/index.htm

[21] New Jersey Institute of Technology. Open Educational Resources: Engineering. http://researchguides.njit.edu/oer/textbooks/subject/engineering

[22] General Services Administration. Office of Design and Construction, Design and Construction Overview. https:/www.gsa.gov/real-estate/design-and-construction-overview

[23] U.S. Army Corps of Engineers. Walla Walla Cost Engineering, Civil Works Cost Engineering, ATR, MCX, and TCX. https:/www.nww. usace.army.mil/Missions/CostEngineering/

[24] Government Accountability Office. Reports and Testimonies. https:/www.gao.gov/reportstestimonies/by-topic/

[25] Amazon.com. Cost page for Construction Estimating Using Excel, 3rd Edition by Steven Peterson. https://www.amazon.com/Construction-Estimating-Using-TradesTechnology/dp/0134405501/ref=sr_1_1? ie=UTF8\&qid=1549248586\&sr=8$1 \&$ keywords $=$ construction + estimating + using + excel (accessed February 1, 2019)

[26] Bluebeam Webstore. http $/ /$ shop.bluebeam.com/SSP\%20Applications/Bluebeam\%20Software/BluebeamWebsto re/Index.html\#Store (accessed February 1, 2019)

[27] Gordian Group. RS Means Online. https:/www.rsmeans.com/products/student/rsm-costdata-student-package-rsmeans-online.aspx (accessed February 1, 2019)

[28] U.S. Marine Corps MCRP 3-40D.12: Construction Estimating. December 2010. 
[29] Smithsonian Institution. Construction Cost Estimating. https:/www.sifacilities.si.edu/ae_center/construction.html

[30] Accreditation Board for Engineering and Technology. Criteria for Accrediting Engineering Technology Programs, 2018 - 2019. https:/www.abet.org/accreditation/accreditationcriteria/criteria-for-accrediting-engineering-technology-programs-2018-2019/\#2

[31] Lumen Learning. Annual OER Report Card. https://lumenlearning.com/annual-oer-reportcard/

[32] Hilton, J., D. Wiley, L. Fischer, and R. Nyland. Guidebook to Research on Open Educational Resources Adoption. Open Textbook Network.

[33] ISKME. OER Commons. https://www.oercommons.org/ 